\title{
LA MÚSICA COMO ELEMENTO SATÍRICO EN LA EDICIÓN DE VÍDEOS DE CONTENIDO POLÍTICO EN YOUTUBE: EL USO DEL AUTOTUNE
}

\author{
Eduardo Viñuela Suárez ${ }^{\mathbf{1}}$ : Universidad de Oviedo. España \\ vinuelaeduardo@uniovi.es
}

\section{RESUMEN:}

La actividad de los prosumidores a raíz de la web 2.0 ha dado lugar a un continuo surgimiento de nuevos fenómenos audiovisuales realizados con software de edición de audio y video. La música juega un papel protagonista en muchos de ellos e interactúa con la imagen y el lenguaje verbal ofreciendo numerosas posibilidades para refrendar o subvertir los significados que cada lenguaje comunica de forma autónoma. En este artículo abordamos el empleo del plug-in AutoTune por parte de los prosumidores para subvertir el significado de los discursos políticos con una intención satírica, una práctica que en los últimos años se ha consolidado alcanzado una dimensión mundial. Esta práctica demuestra cómo la música se utiliza de forma constante para generar un significado diferente, muchas veces contrario, al que expresa el contenido textual de un discurso, funcionando como una herramienta fundamental del polintertaiment con grandes implicaciones ideológicas. Abordamos los parámetros que definen la musicalidad del lenguaje hablado como punto de partida para la creación musical con el AutoTune en esta tipología de vídeos, y profundizamos en este fenómeno con el análisis pormenorizado del ejemplo con mayor repercusión en España en los últimos años: la reciente musicalización que Iván Lagarto hizo del discurso que Rita Barberá pronunció en la Crida de las fallas de 2015.

PALABRAS CLAVE: música - audiovisual - AutoTune - prosumidores - YouTube multimedia - polintertaiment

\section{MUSIC AS A SATIRIC ELEMENT IN EDITING POLITICAL SPEECHES IN YOUTUBE: THE USE OF AUTOTUNE TÍTULO DEL ARTÍCULO EN INGLÉS}

\footnotetext{
${ }^{1}$ Eduardo Viñuela Suárez: profesor de la Universidad de Oviedo. Su campo es investigación es la relación de la música con los medios audiovisuales y las músicas populares urbanas, temas sobre los que ha publicado libros y artículos. Es Vicepresidente de SIBE-Sociedad de Etnomusicología y director del Aula de Música Pop-Rock de la Universidad de Oviedo.
}

Correo: vinuelaeduardo@uniovi.es 


\begin{abstract}
:
Prosumers are constantly generating new audiovisual phenomena since the development of Web 2.0 by using audio and video software in their personal computers. Music is playing a relevant part in many of these phenomena; its interaction with other media, such as visual and verbal languages, is expanding the signifying possibilities of these videos, supporting or challenging the individual meaning of each media. In this paper we approach the use of the plug-in AutoTune in order to undermine with a satiric purpose the meaning of speeches made by politicians in public events. This is a prosumer practice that has been established all over the world in the last years, being a new category in the list of new audiovisual phenomena. AutoTuning demonstrates how music has an enormous power and it is constantly used to challenge the meaning of verbal texts in politic speeches. Thus, music becomes an essential element and a powerful ideological media in most of the audiovisual contents of polintertainment. I am concerned with the parameters that define the musicality of verbal language and the way they are essential in converting these speeches into music by using AutoTune. In order to study this process I analyze the AutoTuning of the speech of Rita Barberá (major of Valencia) during the opening ceremony of Fallas in February 2015, a piece made by Iván Lagarto, which is the most viewed AutoTune video in Spain up to the present day.
\end{abstract}

KEY WORDS: music - audiovisual - AutoTune - prosumer - YouTube - multimedia - polintertaiment.

\title{
1. INTRODUCCIÓN
}

La transformación que en los últimos años han experimentado los medios de producción, distribución y consumo audiovisual ha impulsado nuevos enfoques por parte de los investigadores dedicados a este campo de estudio. Aspectos como la generalización del lenguaje digital o el desarrollo de la web 2.0 han revolucionado el análisis de los fenómenos audiovisuales que circulan por la web poniendo énfasis en los procesos de comunicación, más que en el estudio pormenorizado de los elementos que configuran el texto audiovisual. Esta evolución ha convertido al lenguaje audiovisual en objeto de estudio para nuevas disciplinas al tiempo que ha servido para consolidar el papel de otras que comenzaron a desarrollarse hace unas décadas y que, como en el caso de la musicología audiovisual, constituyen no una disciplina autónoma, sino más bien un "nodo entre disciplinas" (Neumeyer, 2013, p. 3), un punto de encuentro de perspectivas en el que convergen metodologías y perspectivas de análisis.

El estudio de la música en el lenguaje audiovisual ha sabido adaptarse con rapidez al nuevo escenario; así, en los últimos años se están publicando artículos y obras 
colectivas que abordan un amplio abanico de fenómenos. Muchos de los investigadores que fueron referentes en el estudio de la música audiovisual en los años ochenta y noventa (Claudia Gorbman, Michel Chion, Philip Tagg, Anahid Kassabian) se han distanciado de los análisis de la música en el cine, la televisión o los videoclips para abordar el papel de la música en la transmedialidad característica de los fenómenos audiovisuales que hoy en día circulan de forma masiva y viral en internet. En este nuevo contexto resulta difícil establecer fronteras estables entre diferentes géneros audiovisuales, especialmente cuando las sinergias entre géneros y medios han descompuesto categorías en múltiples fenómenos que se suceden, se desarrollan y se consolidan o desaparecen con gran rapidez en internet. Así, por ejemplo, Mathias Bonde Korsgaard ha tratado de analizar la evolución del videoclip elaborando una lista con cerca de una treintena de fenómenos desarrollados a partir del vídeo musical en los últimos años, entre los que encontramos algunos ya consolidados como el lip dub, el shred o el mashup. A pesar del esfuerzo por categorizar este panorama, el autor es consciente de que "aunque extensa, esta lista no es en absoluto completa; nuevos fenómenos similares al vídeo musical toman forma constantemente a través de una desconcertante proliferación de prácticas que es demasiado numerosa para seguirla"2 $(2013$, p. 504).

Aunque en las nuevas categorías de vídeo musical que menciona Bonde Korsgaard hay varias que corresponden a estrategias de la industria musical, las implementadas por los prosumidores son más numerosas y gozan de una gran popularidad en la red. El propio autor propone una redefinición del videoclip como género audiovisual a través del concepto de remediación (Bonde Korsgaard, 2013, p. 508). Esto nos remite a la cultura participativa y a la convergencia mediática que teoriza Henry Jenkins (2006), y muy especialmente al papel que ha jugado YouTube como sitio web de referencia para gran parte de los productos audiovisuales que se consumen en la red, un entorno en el que conviven producciones profesionales y amateur. Según Jenkins,

Al proveer de un canal de distribución para contenido amateur o semiprofesional, YouTube promueve nuevas formas de expresión (...) compartir la misma web da lugar a que estas producciones alcancen una mayor visibilidad que la que alcanzarían si estuviesen en portales aislados. En este sentido, también están expuestas a las prácticas de otros usuarios (2006, pp. 224239).

En efecto, podemos hablar de una "convergencia cultural" (Elsaesser, 2013, p. 16) en el uso de instrumentos para distribuir y consumir los productos culturales (Google, Facebook, Twitter), de un proceso en el que los apocalípticos ven una definitiva estandarización globalizante mientras que para muchos otros supone el fin

\footnotetext{
${ }^{2}$ Todas las traducciones son del autor del artículo.
} 
de una era y la redefinición en las dinámicas en la comunicación interpersonal y masiva. En este contexto de cultura participativa, un producto cultural nunca se considera finalizado, sino que siempre está abierto a modificaciones que, generalmente experimenta a través de la transmedialidad, con la intervención de prosumidores que reinterpretan y reelaboran dicho producto. Lawrence Lessig (2008) se refiere a esta forma de producción colectiva como "leer-escribir", que se opondría al modelo anterior ("solo leer") en el que el consumidor no tiene capacidad de intervención en el producto que consume. El musicólogo Nicholas Cook parte de las reflexiones de Lessig para hablar de la creciente "mentalidad multimedia" (2013) en la que la constante reelaboración de piezas musicales, fruto de las posibilidades que ofrecen los medios digitales, refuerza la definición de música como una práctica y no como un objeto. Cook pone como ejemplo el mashup, en el que un nuevo producto audiovisual surge de la interacción de dos o más obras a priori no relacionadas entre sí.

En el mayor número de casos, los prosumidores obtienen el material con el que elaboran sus obras audiovisuales de DVDs y de distintos sitios de internet, y lo procesan por medio de programas de edición de audio y vídeo. En este estadio de la creación también debemos hablar de convergencia, en este caso tecnológica, ya que la mayor parte de los usuarios utilizan los mismos software, algunos de los cuales forman parte de los sistemas operativos de los propios equipos (Windows Movie Maker o iMovie) o son fácilmente descargables de internet como software libre (Audacity o PowToon), lo que da lugar a cierta estandarización en el uso de filtros y efectos de edición, así como a una uniformidad estética en gran parte de los contenidos creados por sus usuarios. Este determinismo tecnológico también se da en la producción profesional de contenidos y es uno de los pilares para comprender la creciente disolución de fronteras entre géneros audiovisuales a la que nos hemos referido anteriormente.

Las posibilidades que ofrecen los medios digitales también han transformado los entornos de creación hacia los home studio. Si hace unos años, estos estudios amateur funcionaban como un campo de pruebas previo a la grabación profesional, en la actualidad los estándares de calidad que ofrecen permite que formen parte del proceso creativo final. Como señala Paul Harkins,

Al igual que el consumo de música se trasladó de la sala de conciertos a la sala de estar y, de ahí, a la escucha con auriculares (...) la producción musical se ha trasladado del estudio de grabación al hogar y, de ahí, al ordenador portátil, un meta-dispositivo que permite producir, distribuir y consumir música (2010, p. 14). 
Un proceso similar lo podemos encontrar en la producción audiovisual, tanto profesional como amateur, $\mathrm{y}$ ha sido señalado por varios autores como determinante en la definición de una nueva estética audiovisual propia del nuevo contexto digital.

\section{2.- OBJETIVOS}

Uno de los aspectos más generalizados dentro de la nueva estética audiovisual es la reelaboración de contenidos originales. Términos como "remix" (Lessig, 2008), "reciclaje" (López Cano, 2010) o "samplertrofagia" (Caroso, 2014) sirven para designar este tipo de prácticas omnipresentes en los contenidos elaborados por los prosumers y son la base fundamental para la formación de nuevos fenómenos audiovisuales. En este contexto se enmarca la presente investigación, en la que se profundiza sobre las transformaciones del discurso hablado al ser manipulado por el AutoTune, un procesador de audio habitual en los programas de edición digital. La transformación del lenguaje hablado en musical modifica la naturaleza de los productos originales que son utilizados como base para la elaboración de estos vídeos y abre un amplio abanico de posibilidades de creación musical para sus autores. Esta práctica, en boga desde 2009, se ha consolidado como un género en sí mismo, y tiene un alto componente ideológico, ya que generalmente se toman fragmentos de informativos televisivos o discursos de personajes políticos para subvertir el contenido original del discurso hablado. Aspectos como la naturaleza musical del lenguaje hablado, los motivos que guían la elección de un estilo musical concreto, así como las razones que empujan a un prosumidor a elegir un determinado discurso en un determinado momento convierten a esta práctica en un fenómeno relevante de la comunicación actual que cuenta además con un alto grado de aceptación y viralidad en portales como YouTube o en las redes sociales.

\section{3.- METODOLOGÍA: RELACIONAES ENTRE MÚSICA Y LENGUAJE HABLADO}

Las relaciones entre la música y el habla han sido extensamente abordadas en diferentes disciplinas a lo largo de la historia. El propio Charles Darwin aventuraba que los antepasados del ser humano habrían utilizado su voz "para emitir verdaderas cadencias musicales" con las que expresar "distintas emociones como el amor, los celos, el triunfo y el reto a los rivales [así] la imitación de gritos musicales por sonidos articulados ha podido ser el origen de las palabras, traduciendo diversas emociones complejas" (1999, p. 43). Las reflexiones del naturista inglés sirvieron como fundamento para el desarrollo de la musicología evolutiva, una rama de la biomusicología que profundiza en el origen de la música como lenguaje humano. En este sentido, Steven Brown defiende que el origen de ambos medios de expresión humana está en el "musilanguage" (2000), un estadio anterior al desarrollo de ambos, lo que explicaría las características que comparten. 
El estudio de la musicalidad del lenguaje hablado cuenta también con una larga trayectoria que podemos remitir a los tratados sobre oratoria y retórica de la Antigüedad, en especial en lo referente a la elocutio del discurso con una intención persuasiva. Uno de los trabajos pioneros en la Edad Moderna lo constituye An Essay Towards Establishing the Melody and Measure of Speech (1775) del británico Joshua Steele, en el que propone un método para analizar el discurso en base a parámetros musicales (ritmo, acentuación, cadencias, etc.). Esta suerte de análisis prosódico del lenguaje hablado ha continuado hasta la actualidad especialmente ligado a la comunicación pública en forma de discursos. Así, en "The music of speech: layering Musical Elements to Deliver Powerful Messages" (2011), un grupo de investigadores de la Universidad de Harvard liderado por Steven D. Cohen analiza la musicalidad de los discursos de varios líderes políticos estadounidenses (Bill Clinton, Jesse Jackson o Elizabeth Glaser) partiendo de la cualidad de la voz humana como instrumento musical, y establecen cinco parámetros (tempo, dinámica, altura, timbre y ritmo) que demostrarían cómo "los hablantes pueden usar estos elementos musicales para crear imágenes musicales que dejen una impresión determinada en los oyentes" (p. 16). La musicalidad que se imprime a un discurso crea una atmósfera, genera un sentido de lo que se quiere comunicar más allá del contenido del mismo, al tiempo que sirve para establecer su estructura, enfatizando o disimulando argumentos y reforzando determinados términos o conceptos que se quieran transmitir.

La cualidad musical de los discursos hablados es aún un campo de investigación en desarrollo que cuenta con una menor trayectoria en la comunicación pública que otros como la gestualidad y el lenguaje corporal. Sin embargo, es posible encontrar parámetros musicales en prácticamente cualquier enunciación humana, y especialmente en la impostación de la voz que caracteriza a cualquier discurso público, lo que lo convierte en uno de los formatos hablados más cercanos al canto. En el terreno musical, existen numerosos ejemplos de repertorios que se encuentran a medio camino entre el canto y el habla, en los que el lenguaje hablado forma parte de la estética musical; la cantilación del gregoriano o el spoken word son sólo dos ejemplos muy distantes, tanto en carácter como en el tiempo, que ilustran cómo esta ambigüedad ha estado siempre presente en la historia de la música.

Sin embargo, la relación entre música y lenguaje hablado entendidos no como integración, sino como interacción de dos sistemas de significación autónomos supone una relación multimedia en la que los significados de cada lenguaje se ven afectados generando en la relación que se establece entre ambos un significado nuevo. En este sentido, resulta significativo que determinados contenidos difundidos a los medios de comunicación, como los mensajes institucionales o los discursos políticos carezcan de música, más allá de la que se escucha para introducirlos o una vez finalizados, especialmente en celebraciones y mítines electorales. En los medios de comunicación, las entrevistas y los programas de informativos también carecen de música, sólo se escucha en la cabecera y cierre del programa y, excepcionalmente, 
en reportajes generalmente ligados a contenidos culturales o deportivos ${ }^{3}$. Son los programas de polintertaiment los que constantemente utilizan la música para abordar temas políticos y de actualidad, dando como resultado un tratamiento satírico y humorístico de los mismos. La música tiene la capacidad de tergiversar el sentido de lo que se pretende transmitir a través de un discurso hablado, además de unas connotaciones lúdicas y de entretenimiento que la hacen inapropiada para contenidos serios. Así, "la música es utilizada como un comentario irónico de lo que vemos para distanciar a los espectadores de la acción y hacerles sentir más sagaces" (Frith, 2003, p. 187). Incluso en publicidad, terreno en el que la música es un elemento habitual desde el nacimiento del jingle, hay determinados productos que evitan su uso por los efectos negativos que se puedan generar en la transmisión del mensaje. Como señala, José Antonio Gómez, tradicionalmente en los anuncios de medicamentos o de productos de limpieza la música podría dar sensación de enmascarar, de no ser honesto, de no ser serio (Gómez, 2005, p. 226).

Esta discriminación en el tratamiento de los contenidos de los medios de comunicación se refleja en la producción y en la estética de los mismos. Así, por ejemplo, la realización audiovisual de un programa de informativos es mucho más pausada y conservadora que la de un programa de polintertaiment, y tradicionalmente los programas de entretenimiento o destinados a la audiencia juvenil han servido de campo de pruebas para técnicas de realización que con el tiempo se han consolidado. Sirvan de ejemplo las producciones de Valerio Lazarov para TVE a finales de los sesenta y principios de los setenta. Esto confirma cómo la estética consolidada en la difusión de asuntos considerados serios y relevantes, entre los que se incluyen los discursos institucionales y políticos, es sobria, conservadora y evita el uso de la música.

Si bien encontramos numerosos ejemplos de un empleo satírico de la música en los medios audiovisuales a lo largo de la historia, podemos afirmar que en los últimos años esta práctica se ha incrementado debido a la cultura participativa de los prosumidores en internet. En España estas prácticas no son muy numerosas; en un estudio reciente se apuntaba que, en nuestro país, "el prosumidor mediático del politainment se caracterizaría por ejercer un prosumo muy reducido en la creación de mensajes y un consumo mayoritario" (Berrocal, Campos y Redondo, 2014, p. 11). Sin embargo, el impacto que alcanzan estos productos en un espacio de tiempo breve es muy significativo y es un estímulo para estos creadores, que están atentos a la actualidad para seleccionar como protagonistas de sus vídeos temáticas, acontecimientos y personajes que tengan una notable repercusión en los medios ${ }^{4}$. La

\footnotetext{
${ }^{3}$ La música se está introduciendo cada vez en más en los programas de informativos y, a menudo, sirve para estructurar secciones.

${ }^{4}$ Muchos de estos vídeos de prosumidores son incluidos en programas de televisión ("El Intermedio", "Zappeando", "El hormiguero"), lo que aumenta su difusión y popularidad. Esto refuerza los argumentos que hablan de una tendencia creciente en los últimos años en la que "la televisión y los medios impresos son una cámara de resonancia para YouTube" (Vernallis 2013: p. 15).
} 
proliferación de la cultura participativa instaurada en los medios digitales implica que haya un creciente número de usuarios de internet que "participan en discusiones de forma gratuita, y esta proliferación de discusiones implica que haya más personas generando, a su vez, más críticd" (Sexton, 2007, p. 6). El elevado número de visitas y comentarios que atesoran estas producciones, así como la viralidad que alcanzan en redes sociales, son formas de participación activa por parte de los consumidores de estas producciones y demuestran un grado de implicación muy diferente al tradicional consumo pasivo. En este sentido, no es de extrañar que los personajes políticos y sus discursos en actos públicos sean en muchas ocasiones los protagonistas de estas producciones, y que una de las estrategias más habituales para "comentar" lo que tratan de comunicar estos políticos sea la incorporación de otro sistema de significación, de un lenguaje como la música, que modifique el sentido del discurso o cambie la naturaleza del mismo convirtiéndolo en una canción.

Este modo de proceder implica la elección o composición por parte del prosumidor de una pieza musical para construir el nuevo sentido del discurso en el vídeo, y esto conlleva una serie de decisiones relacionadas tanto con los significados que van asociados a los diferentes estilos y géneros musicales, como con aspectos formales relacionados con la edición audiovisual. El significado de un género musical "no está sólo en la música, sino también en los cuerpos y las mentes de grupos de personas que comparten determinados valores" (Holt, 2007, p. 2); así, existen una serie de códigos compartidos en una sociedad que otorgan determinados valores a los diferentes géneros musicales, lo que le permite al prosumidor de estas producciones utilizar una pieza musical para dar nuevos significados al original. Asimismo, existe una serie de estilos musicales que se repiten en muchos de estos vídeos, mientras que otros son raras veces utilizados; el rap y la música electrónica son los que más abundan y, más allá de que sean estilos en boga en la actualidad, las razones para este predominio las encontramos en los parámetros musicales que los definen. Como señala Allan Cameron, en la música electrónica "parámetros como el timbre, la reverberación y el ritmo suelen ser más relevantes que la melodía y la letra" (2013, p. 753). De la misma forma, en el rap el énfasis generalmente se encuentra en el ritmo de la base musical sobre la que el rapero interpreta una letra en la que suele primar la rima y el ritmo de la letra por encima de la melodía; no en vano, en numerosas ocasiones, el rapero más que entonar declama la letra, evitando crear una melodía.

Estas cualidades convierten a estos estilos musicales en los preferidos por los prosumidores para sus creaciones, ya que facilitan y guían la edición de los vídeos marcando puntos de sincronía audiovisual y cortes de plano en el montaje que permiten trabajar como en la edición de un videoclip. Si examinamos algunos de los ejemplos más populares en los últimos años, desde las parodias creadas a partir de la frase "¿por qué no te callas?" que el rey Juan Carlos dirigió a Hugo Chávez en la cumbre iberoamericana de 2007, hasta otras más recientes, como las generadas a partir del discurso de Ana Botella en la presentación de la candidatura de Madrid 
como sede de los Juegos Olímpicos de 2020 (septiembre de 2013), en todas ellas predomina claramente el empleo de la música electrónica y el rap como estilos musicales elegidos. Lo mismo sucede en los vídeos creados a partir del discurso de Pablo Iglesias en la Puerta del Sol de Madrid con motivo de "La marcha del cambio" en enero de 2015, que ha sido musicalizado por varios prosumidores para convertirlo en diferentes temas de rap ${ }^{5}$. En este caso, la elección del estilo musical es aún más significativa si tenemos en cuenta los valores de reivindicación y denuncia social asociados al hip hop como género musical, acordes con la imagen pública de Pablo Iglesias.

La intención de los prosumidores a la hora de poner banda sonora a estos discursos, así como los diferentes significados que en cada caso se derivan por parte de los consumidores y que en gran medida se reflejan en los comentarios de cada vídeo precisarían de un análisis pormenorizado de cada caso. Por otra parte, la variedad y el constante surgimiento de nuevos procedimientos a la hora de elaborar este tipo de vídeos hace difícil abordarlos de forma unitaria. Por esta razón, en el siguiente apartado nos centraremos en el análisis de una práctica muy extendida en la musicalización de discursos políticos que podríamos considerar una subcategoría dentro de este tipo de vídeos; se trata del empleo del plug-in AutoTune en el procesamiento de la voz para transformar los discursos originales, y analizaremos en profundidad la creación del músico Iván Lagarto a partir del discurso de Rita Barberá en la Crida de las fallas de 2015, el ejemplo con mayor repercusión mediática en España este año hasta la fecha.

\section{4.- DISCUSIÓN: EL AUTOTUNE COMO HERRAMIENTA DE MUSICALIZACIÓN DEL DISCURSO POLÍTICO}

AutoTune es el nombre de un procesador de audio creado por Andy Hildebrand en 1997. En la actualidad está disponible como plug-in en programas de edición de audio, como ProTools, Cubase o FL studio XXL. Este procesador permite la manipulación digital de la altura del sonido, lo que le ha valido una gran popularidad, no exenta de polémica, en la producción musical. Además de ser utilizado de forma disimulada para la corrección de errores de afinación en la edición de grabaciones musicales, desde su creación se experimentó con su uso deliberado como recurso estético en diversas producciones musicales, siendo la canción "Believe" (1998), interpretada por Cher, la pieza que dio al AutoTune una fama internacional. Desde entonces, son muchos los artistas que han utilizado este procesador, algunos incluso lo han convertido en una marca de estilo (T-Pain, Kane Wes o Eurodance), una tendencia que algunos autores han interpretado como un exponente del contexto digital en el que vivimos. Así, para Joseph Auner, "el extendido empleo del AutoTune en las voces de la música popular urbana demuestra el atractivo que ha alcanzado el ciborg' (2012, p. 145). En cierto sentido, podemos interpretar esta tendencia como

\footnotetext{
${ }^{5}$ El usuario de YouTube "bukanero97" ha publicado un vídeo en el que el discurso aparece presentado como un álbum completo de rap con diferentes cortes a los que ha puesto título, y ofrece un enlace para descargarlo gratuitamente. http://goo.gl/Ge632H (27-4-2015)
} 
una nueva corriente estética en la música popular que trata la voz como un instrumento más dentro de la producción musical.

La incorporación del AutoTune al fenómeno de los vídeos de prosumidores en YouTube comienza en 2009, cuando el grupo Gregory Brothers inició la serie AutoTune the news, mostrando vídeos de noticiarios de las principales cadenas de televisión estadounidenses con el audio procesado a través del AutoTune y el añadido de una base instrumental compuesta expresamente para el vídeo. El montaje de las secuencias se modifica para construir un discurso satírico y con una estructura de canción (estrofas, puente, estribillo), de manera que todos los personajes que aparecen en el vídeo parecen estar cantando y actuando. Los miembros de Gregory Brothers también aparecen en estos vídeos, interpelando a los personajes del vídeo y cantando junto a ellos.

Esta serie de vídeos alcanzó una enorme popularidad desde sus inicios, con millones de visitas. Su vídeo más visto hasta la fecha, "The bed intruder", fue publicado el 31 de julio de 2010, y alcanzó 7,1 millones de reproducciones en el primer mes, convirtiéndose en el vídeo más visto del año en YouTube ${ }^{6}$. Asimismo, fue comercializado como single en iTunes, llegando al puesto 89 en la lista de los temas más vendidos ${ }^{7}$. Además, la serie AutoTune the news marcó la pauta para otros prosumidores en todo el mundo que imitaron esta práctica, consolidando un nuevo formato o género dentro de los nuevos fenómenos audiovisuales en la red. La forma de trabajar revela una clara preocupación por captar la musicalidad del discurso hablado a la hora de componer la pieza. Como señala el músico Michael Gregory en una entrevista publicada por la revista Wired,

Quería escuchar los contornos de la voz [de Antoine Dodson] y la forma en la que estaba expresando sus emociones. He trabajado mucho en este aspecto, de manera que cuando le oigo hablar puedo escuchar la melodía, y esa melodía adquiere diferentes connotaciones en función del tono en el que la pongas. Después compongo la parte instrumental y la incluyo en la edición musical $^{8}$.

Esta forma de trabajar precisa conocimientos musicales básicos por parte del prosumidor, que debe saber generar y armonizar la melodía de la pieza para crear la canción. Así, "estos artistas reorganizan intencionadamente la sintaxis, la estructura fonética y la semántica para generar una melodía" (Levine, 2013, p. 2). El proceso para convertir con éxito el habla en música implica una serie de destrezas, y esta es quizás la razón por la cual esta práctica no es tan masiva como otros formatos de vídeos en la red. De esta forma, el impacto que genera una producción de este tipo

\footnotetext{
${ }^{6}$ YouTube Rewind 2010 http://goo.gl/FaF6Fp (22-4-2015)

${ }^{7}$ Revista Billboard, agosto de 2010, http://goo.gl/34lpp8 (17-4-2015)

${ }^{8}$ Entrevista en Wired (13/08/2010) http://goo.gl/eK7W37 (14-4-2015)
} 
es aún mayor, ya que es una única pieza y no sus derivados la que se convierte en viral. Si los Gregory Brothers han popularizado esta práctica a nivel internacional, el músico Iván Lagarto ha sabido adaptarla al contexto español, realizando este tipo de vídeos con diferentes frases populares en nuestro país, varias extraídas de discursos de políticos como Esperanza Aguirre, Artur Mas o Rita Barberá. Iván Lagarto es un polifacético músico catalán con estudios de grado medio en el Aula de Música Moderna y Jazz de Barcelona ${ }^{9}$. Además de componer para televisión y publicidad, ha grabado sus propias canciones y acompaña a la guitarra al monologuista Berto Romero en sus actuaciones por España. Su canal de YouTube cuenta con una cuarentena de vídeos producidos por él, todos ellos musicalizaciones de fragmentos hablados procesados con AutoTune.

El vídeo que mayor éxito ha tenido hasta el momento es la musicalización del discurso de Rita Barberá, alcaldesa de Valencia, en la Crida de las Fallas de 2015, el acto oficial de apertura de estas fiestas. Esta producción, publicada en YouTube el 23 de febrero (al día siguiente del discurso de la Crida) con el título "El caloret" ${ }^{\prime 10}$, se convirtió rápidamente en un fenómeno viral que en tres días superó las cuatrocientas mil reproducciones ${ }^{11}$, y que dos meses después había superado el millón setecientas mil reproducciones. Esta producción se benefició de la polémica en torno al dudoso dominio del valenciano que demostró la alcaldesa en su discurso, que la misma noche de la Crida se convirtió en viral en las redes sociales, llegando a superar el medio millón de reproducciones en YouTube y convirtiendo en trending topic hashtags como \#Rita, \#crida2015 o, el más popular, \#caloret ${ }^{12}$.

No es casualidad que el hashtag más popular sea también el título de la composición de Lagarto, y es que Barberá repite el término hasta en ocho ocasiones en la misma frase. Por otro lado, el cuestionado término "caloret" ${ }^{\prime 13}$ se erigió rápidamente como representativo del desafortunado discurso de la alcaldesa de Valencia. Pero, a nuestro juicio, la popularidad de este discurso no es la única razón para que Iván Lagarto lo haya elegido como protagonista de uno de sus vídeos, cuestiones como la repetición de varias frases y términos ("en esta nit", "caloret" o "ja estem en falles"), así como la característica entonación en la pronunciación del discurso son claves para comprender las razones que pudieron llevar a Lagarto a elaborar el exitoso vídeo. El discurso ${ }^{14}$ mantiene en todo momento un ritmo lento y una elevada intensidad, y se articula con una estructura binaria por una entonación muy marcada de apertura y cierre que se establece desde el principio: "Poble valencià", "falleres i fallers". En ambos casos la primera palabra es pronunciada con una direccionalidad hacia el agudo y en la segunda hacia el grave, buscando la pausa. A continuación, sucede lo

\footnotetext{
${ }^{9}$ Entrevista a Iván Lagarto publicada en http://goo.gl/Y02kvn (19-4-2015)

${ }^{10} \mathrm{http}: / /$ goo.gl/tQ2qvc (29-4-2015)

${ }_{11} \mathrm{http}: / /$ goo.gl/RouCKe $(18-4-2015)$

12 http://goo.gl/1wc2D0 (18-4-2015)

${ }^{13}$ El término aceptado por la Acadèmia Valenciana de la Llengua sería "caloreta".

${ }^{14}$ Discurso de Rita Barberá en la Crida 2015 http://goo.gl/Vz1rUr (29-4-2015)
} 
mismo con "en esta nit / fallera", "en esta nit / de festa", "en esta nit / de il·lusió y alegría" con un perfil de entonación en arco que va hacia al agudo en la primera parte y hacia el grave en la segunda, exceptuando en el término "alegría", que vuelve al agudo para preparar la continuidad del discurso. Este tipo de articulación se repite en la yuxtaposición "el caloret / faller", "el caloret / sin duda", "el caloret del foc / i la flama», "el caloret / de la primavera", "el caloret / faller", "el caloret / de la llum", "el caloret / de la il/lusió", para concluir con un demarcado y épico "ija / estém / en falles!", que no solo se pronuncia enfatizando cada una de las tres partes, sino que además es repetido hasta tres veces por la alcaldesa.

Iván Lagarto toma varios fragmentos para construir una estructura de canción (estribillo, estrofa, pre-estribillo, estribillo, cambio, estribillo) con un ritmo acelerado y un compás de cuatro partes en el que predomina la síncopa. Esto da como resultado una base rítmica de ska construida con una instrumentación que tiene al piano, al viento metal (ambos sintetizados) y a la guitarra eléctrica como protagonistas. La canción está en la tonalidad de Re mayor, un registro significativamente más alto que el discurso hablado, fruto en parte de la aceleración de la locución, y transcurre por los grados fundamentales de la tonalidad (I-IV-V) con excepción del cambio (II-V-I-IV). Por su parte, la melodía no supera el ámbito de cuarta (Re-Sol), tomando las notas de ambos extremos como las fundamentales en torno a las cuales se construye la melodía. Este parámetro de la canción refuerza la relación de la música con el discurso hablado, remarcando la direccionalidad del perfil melódico que ya hemos identificado en el discurso hablado.

Por otra parte, a lo largo del minuto y medio que dura la canción, se observa una constante variedad de texturas que dan lugar a diferentes grados de intensidad. El estribillo con el que arranca la canción concentra la instrumentación en el acento agudo de la palabra "caloret", marcando la parte fuerte del compás. La expectación que genera esta introducción resuelve en la repetición del estribillo, esta vez con toda la instrumentación y el bullicio puntual de una multitud que se introduce de forma repetida en cada compás con evidente función rítmica. De la misma forma, en el cambio, la canción parece quedar suspendida: la estructura armónica cambia y comienza en un acorde en tonalidad menor (Mi menor), el pulso deja de ser marcado, la síncopa desaparece y la instrumentación se reduce al mínimo. Este tipo de estructura es habitual en la música electrónica y suele resolverse de forma progresiva, sumando texturas y ganando intensidad hasta volver al pulso regular inicial; en este caso, la brevedad de la pieza lleva a su autor a resolver de forma brusca, pero efectiva, en un nuevo estribillo con el que concluye la canción.

Son numerosos los aspectos que hacen atractiva a esta pieza; lo convencional de sus parámetros formales contribuye a su fácil asimilación, pero además el pulso marcado y regular en el ritmo y la constante repetición de elementos, tanto musicales como visuales, se corresponden con una de las características más habituales en la nueva 
estética audiovisual (Vernallis, 2013, p. 130). En un discurso hablado, la repetición de un término sirve para reforzar, enfatizar y darle una mayor relevancia; son frecuentes los análisis que hacen recuento de los términos más utilizados en discursos de líderes políticos para extraer conclusiones acerca de los mensajes que buscan transmitir. En la pieza de Iván Lagarto el énfasis en la repetición de términos se refuerza con la progresión melódica; así, en el estribillo la primera vez que se pronuncia "caloret" lo hace con la secuencia melódica Re-Mi-Fa\#, mientras que la segunda lo hace con la secuencia Mi-Fa\#-Sol, en una progresión melódica de medio tono que consigue destacar este término en la canción. Algo similar sucede en el cambio de la canción, donde la frase "la llegá de... I'arribada de" también cuenta con una progresión melódica, en este caso de un tono (Re-Mi-Re-Mi / Re-Mi-Re-Fa\#), que enfatiza la corrección idiomática del castellano al valenciano que Barberá hizo durante el discurso.

Por otro lado, varios de los comentarios al vídeo en YouTube apuestan por esta pieza como "canción del verano", y aunque esta etiqueta no constituye un estilo en sí mismo, la repetición de estribillos es una de las características habitual en ese tipo de canciones. La repetición no es solo musical, sino también visual, ya que para conseguir la sincronización verbo-labial se recurre a las mismas imágenes a lo largo del vídeo.

El resultado es una producción satírica que busca explicitar el escaso dominio del valenciano por parte de Rita Barberá, convirtiendo el malogrado discurso en una canción festiva. El autor del vídeo define la música como "pachanga", entendida como música de fiesta y, en efecto, el ritmo vivo, las síncopas características del ska y los perfiles melódicos creados con el AutoTune confirman este sentido. Así, un acto solemne como el discurso de la Crida es parodiado reforzando su carácter desenfadado con una música festiva, para enfatizar así lo desafortunado de la intervención de la alcaldesa en esta edición de 2015.

\section{5.- CONCLUSIONES}

El nuevo panorama audiovisual a raíz del desarrollo de la web 2.0 ha transformado las dinámicas de producción, distribución y consumo de los productos audiovisuales y ha facilitado el surgimiento de nuevas prácticas y fenómenos protagonizados en gran medida por los prosumidores. El nacimiento de estas nuevas prácticas exige un cambio de paradigma en la investigación de la comunicación audiovisual que en la actualidad está siendo fundamentado en conceptos como la cultura participativa o las narrativas transmediáticas. En este contexto, el análisis de la música en los medios audiovisuales precisa una constante renovación para abordar el papel de este lenguaje en fenómenos como la musicalización de discursos hablados a través del AutoTune que analizamos en este trabajo. 
La música es un lenguaje muy presente y con gran capacidad de significación en los fenómenos audiovisuales que se desarrollan en la red. Su empleo por parte de los prosumidores en sus producciones demuestra el manejo de unos códigos vigentes en la sociedad actual y, por lo tanto, la capacidad de la música para subvertir los significados establecidos en otros lenguajes. La manipulación de un parámetro como la altura del sonido con el AutoTune transforma su naturaleza y es capaz de convertir el discurso hablado en cantado.

El gran impacto de algunas de estas piezas las convierte en herramientas de participación política de la ciudadanía, tanto para quienes las crean como para quienes las difunden en sus redes sociales. Si analizamos el impacto social de "El caloret", una búsqueda en Google Trends sirve para comprobar que Rita Barberá alcanzó la máxima popularidad de los últimos años en la red durante la semana en la que se publicó el vídeo ${ }^{15}$. Si bien este tipo de producciones pueden ser vistas como mero entretenimiento, "entendidos como una forma de empoderamiento entre los ciudadanos y los votantes, no son consumidos simplemente como bromas, sátiras o parodias" (Edwards, 2012, p. 30). Por esta razón, deben ser tenidos en cuenta en los estudios de comunicación y analizados desde diferentes perspectivas para comprender mejor los mecanismos que rigen su producción difusión y consumo. En este contexto se enmarca este trabajo como una reflexión acerca de la delgada frontera entre lenguaje hablado y el musical, que no es más amplia que la existente entre la solemnidad de un discurso público y la sátira política.

\section{6.- REFERENCIAS}

AUNER, J. (2012). "Losing your Voice: Sampled Speech and Song from the Uncanny to the Unremarkable", en Ekman, U. (Ed.), Throughout: Art and Culture Emerging in an Age of Ubiquitous Computing (pp. 135-151). Massachusetts: MIT Press.

BERROCAL, S.; Campos, E. \& Redondo M. (2014). "Prosumidores mediáticos en la comunicación política: el «politainment» en YouTube". Comunicar, 43, pp. 1-13 (DOI: $10.3916 / C 43-2014-06)$

BONDE KORSGAARD, M. (2013). "Music Video Transformed", en Richardson, J.; Gorbman, C. \& Vernallis, C. (Eds.), The Oxford Handbook of New Audiovisual Aesthetics (pp. 501-521). Oxford: Oxford University Press. (DOI: 10.1080/03007766.2014.939456)

${ }^{15}$ https://goo.gl/Y4J9V6 (6-4-2015) 
BROWN, S. (2000). "The musilanguage Model of music Evolution", en Waillin, N.; Merker, B. \& Brown, S. (Eds.), The origins of music (pp. 271-301). Massachusetts: MIT Press.

CAMERON, A. (2013). "Instrumental Visions: Electronica, music video, and the environmental interface", en Vernallis, C.; Herzog, A. \& J. Richardson (Eds.), The Oxford Handbook of Sound and Image in Digital Media (pp. 752-772). Oxford: Oxford University Press. (DOI: 9780199757640.001.0001)

CAROSO, L. (2015). "Ethnomusicology in Cyberspace: Samplertrofagia and Virality in YouTube Videos", en Ulhôa, M.; Azevedo, C. \& Trotta, F. (Eds.), Made in Brazil: Studies in Popular Music (pp. 163-172). London: Routledge.

COHEN, S.; WEI, T.; DeFRAIA, D. \& DRURY, C. (2011). "The music of speech: layering Musical Elements to Deliver Powerful Messages". Relevant Rhetoric, Vol. 2, pp. 1-24, http://goo.gl/QJFVbM Consultado el 15-4-2015.

COOK, N. (2013). "Beyond music: mashup, multimedia mentality and intellectual property", en Richardson; J., Gorbman; C. \& Vernallis, C. (Eds.), The Oxford Handbook of New Audiovisual Aesthetics (pp. 53-76). Oxford: Oxford University Press. (DOI: 10.1080/03007766.2014.939456)

DARWIN, C. (1999). El origen de las especies. Madrid: Alba.

EDWARDS, R. (2012). "Flip the Script. Political Mashups as Transgressive texts", en Gournelos, T. \& Gunkel, D. (Eds.), Transgression 2.0: Media, Culture and the Politics of a Digital Age (pp. 26-41). New York: Continuum.

ELSAESSER, T. (2013). "Digital cinema: convergence or contradiction", en Vernallis, C.; Herzog, A. \& Richardson, J. (Eds.), The Oxford Handbook of Sound and Image in Digital Era (pp. 13-44). Oxford: Oxford University Press. (DOI: 9780199757640.001.0001)

FRITH, S. (2003). "Look! Hear! The Uneasy Relationship of Music and Television". En Frith, S. (Ed.), Taking Popular Music Seriously (pp. 183 -196). London: Ashgate. (DOI: http://dx.doi.org/10.1017/S0261143010000267) 
GÓMEZ, J. A. (2005). "Lo que no venda cántelo. Algunas reflexiones sobre el papel de la música en la publicidad: de los viejos pregones a los spots de televisión", en Olarte, M. (Ed.), La Música en los medios audiovisuales (pp. 225-265). Salamanca: Plaza.

HARKINS, P. (2010). "Appropiation, Additive Approaches and Accidents: the sampler as ompositional tool and recording dislocation". IASPM Journal, vol 1, $\mathrm{n}^{\circ} 2$, pp. $\quad 1-19$ http://goo.gl/XELd9I Consultado el 25-4-2015. (DOI: http://dx.doi.org/10.5429/333)

HOLT, F. (2007). Genre in Popular music. Chicago: University of Chicago Press.

JENKINS, H. (2006). Convergence Culture: Where Old and New Media Collide. New York: New York University Press. (DOI: 10.1111/j.1460-2466.2007.00359_2.x)

LESSIG, L. (2008). Remix: Making Art and Commerce Thrive in the Hybrid Economy. London: Penguin Press.

LEVINE, S. (2013). "\#WhatwouldChomskydo: Language Structure in the Realm of New Media". Communication, Culture \& Technology, 748, http://goo.gl/IclE87 Consultado el 12-4-2015.

LÓPEZ CANO, R. (2010). "La vida en copias. Breve cartografía del reciclaje musical digital". Revista LIS, Año III, 5, pp. 171-185, semioticafernandez.com.ar/wpcontent/uploads/2012/03/14-LIS5-ReciclajeMusicalDigital-RLC.pdf Consultado el 2704-2015.

NEUMEYER, D. (Ed.) (2013). The Oxford Handbook of Film Music Studies. Oxford: Oxford University Press. (DOI: 10.1093/oxfordhb/9780195328493.001.0001)

SEXTON, J. (Ed.) (2007). Music, Sound and Multimedia: from Live to the Virtual. Edinburg: Edinburg University Press. 
STEELE, J. (1775). An Essay Towards Establishing the Melody and Measure of Speech. http://goo.gl/WecuZS Consultado el 10-4-2015

VERNALLIS, C. (2013). Unruly Media: Youtube, Music Video, and the new Digital Cinema. Oxford: Oxford University Press. 